\title{
Inquérito epidemiológico sobre plantas tóxicas das mesoregiões Central e Oeste do Rio Grande do Norte
}

\author{
Epidemiological survey about toxic plants from the central and west regions of Rio Grande do \\ Norte state, Brazil
}

Severino Antonio Geraldo Neto ${ }^{\mathrm{I}}$ Sidnei Miyoshi Sakamoto ${ }^{\mathrm{II}}$ Benito Soto-Blanco ${ }^{\mathrm{III}}$

\section{RESUMO}

Foi realizado um estudo para determinar as plantas tóxicas incriminadas como de interesse zootécnico em 35 municípios das mesorregiões Central e Oeste do estado do Rio Grande do Norte (RN). Foram entrevistados 180 produtores, 20 médicos veterinários, 12 técnicos agrícolas e 5 agrônomos. Os dados obtidos nas entrevistas foram compilados e analisados com auxílio do programa Epi Info versão 6.04. As plantas tóxicas relatadas pelos entrevistados como causadoras de diversos surtos foram Ipomoea asarifolia, Aspidosperma pyrifolium, Indigofera suffruticosa, Manihot carthaginensis subsp. glaziovii, Amorimia septentrionalis, Tephrosia cinerea, Anadenanthera colubrina var. cebil, Marsdenia megalantha, Anacardium occidentale, Cnidoscolus quercifolius, Crotalaria retusa, Froelichia humboldtiana, Ipomoea carnea, Leucaena leucocephala, Manihot esculenta, Mimosa tenuiflora, Nerium oleander, Prosopis juliflora, Ricinus communis, Sorghum bicolor, Sorghum halepense e Urochloa (Brachiaria) decumbens.

Palavras-chave: intoxicações por plantas, animais de produção, semiárido, epidemiologia.

\section{ABSTRACT}

A study was conducted aiming to determine the plants species poisoning of zootechnical interest in 35 cities from Central and West regions of Rio Grande do Norte state, Brazil. It was interviewed 180 farmers, 20 veterinarians, 12 agriculture experts, and 5 agronomists. Data obtained in the interviews were compiled and analyzed using the software Epi Info version 6.04. The plant species responsible by greater number of poisoning outbreaks were Ipomoea asarifolia, Aspidosperma pyrifolium, Indigofera suffruticosa, Manihot carthaginensis subsp. glaziovii, Amorimia septentrionalis, Tephrosia cinerea, Anadenanthera colubrina var. cebil, Marsdenia megalantha, Anacardium occidentale, Cnidoscolus quercifolius, Crotalaria retusa, Froelichia humboldtiana, Ipomoea carnea, Leucaena leucocephala, Manihot esculenta, Mimosa tenuiflora, Nerium oleander, Prosopis juliflora, Ricinus communis, Sorghum bicolor, Sorghum halepense, and Urochloa (Brachiaria) decumbens.

Key words: plant poisoning, livestock, semiarid, epidemiology.

\section{INTRODUÇÃO}

As plantas tóxicas de interesse pecuário são aquelas que, quando ingeridas pelos animais domésticos, em condições naturais, causam danos à saúde ou mesmo morte dos animais. No Brasil, foram descritas cerca de 130 espécies de plantas tóxicas (TOKARNIA et al., 2012), mas esse número vem crescendo continuadamente. Trabalhos de campo que levantaram a ocorrência de intoxicações por plantas foram realizados na região do Seridó do Rio Grande do Norte (SILVA et al., 2006), Sertão da Paraíba (ASSIS et al., 2009), Norte do Piaú (MELLO et al., 2010), Norte do Tocantins (COSTA et al., 2011a, 2011b) e Central de Rondônia (SCHONS et al., 2012). Nesses trabalhos, foi possível a determinação da frequência das intoxicações e a identificação de possíveis novas espécies tóxicas. Este trabalho teve como objetivo determinar as plantas tóxicas e as intoxicações por elas causadas em 35 municípios das mesorregiões Central e Oeste do estado do Rio Grande do Norte, assim como determinar como estas estão distribuídas.

'Programa de Pós-graduação em Ciência Animal, Universidade Federal Rural do Semi-Árido (UFERSA), Mossoró, RN, Brasil.

IIDepartamento de Ciências Animais, UFERSA, Mossoró, RN, Brasil.

IIIDepartamento de Clínica e Cirurgia Veterinárias, Universidade Federal de Minas Gerais (UFMG), Av. Antônio Carlos 6627, CP 567, 30123-970, Belo Horizonte, MG, Brasil. E-mail: benito.blanco@pq.cnpq.br. *Autor para correspondência. 


\section{MATERIAL E MÉTODOS}

O trabalho foi realizado nas mesorregiões Central e Oeste do RN (Figura 1). Foram visitados 35 municípios, os quais possuem uma área de $17.875,23 \mathrm{~km}^{2}$ (IDEMA, 2010). Foram entrevistados 180 produtores, 20 médicos veterinários, 12 técnicos agrícolas e 5 agrônomos. Foram utilizados três questionários semelhantes aos utilizados por SILVA et al. (2006). Os questionários 1 e 2 foram aplicados a todos os entrevistados e o formulário 3 somente aos que tinham conhecimento a respeito de casos naturais de intoxicação por essas plantas. No questionário 1, o entrevistado foi questionado sobre a presença de plantas tóxicas conhecidas na região Nordeste. Essas perguntas foram formuladas mencionando o nome comum da planta e, em caso de dúvidas, foi mostrada uma foto dela. No questionário 2, o entrevistado foi questionado sobre a presença de plantas que não estavam incluídas no questionário 1 , sendo consideradas neste trabalho apenas espécies que já tiveram algum trabalho experimental confirmando sua toxicidade. No formulário 3, foi questionado sobre casos de intoxicações observados pelos entrevistados.

Os dados obtidos nas entrevistas foram compilados e analisados com auxílio do programa Epi Info versão 6.04 .

\section{RESULTADOS}

Nas 217 entrevistas feitas neste estudo, foram relatados 1.176 surtos de intoxicação por plantas comprovadamente tóxicas, apresentados nas tabelas 1 e 2 .

Dos casos relatados como causados por Aspidosperma pyrifolium, em 12 (17,1\%) dos caprinos e um $(1,43 \%)$ dos bovinos acometidos, foi atribuída a ocorrência de malformações, caracterizadas por flexura dos membros pélvicos, prognatia, braquignatia, microftalmia, dermoide ocular e atresia anal, sendo que estes cabritos não morreram.

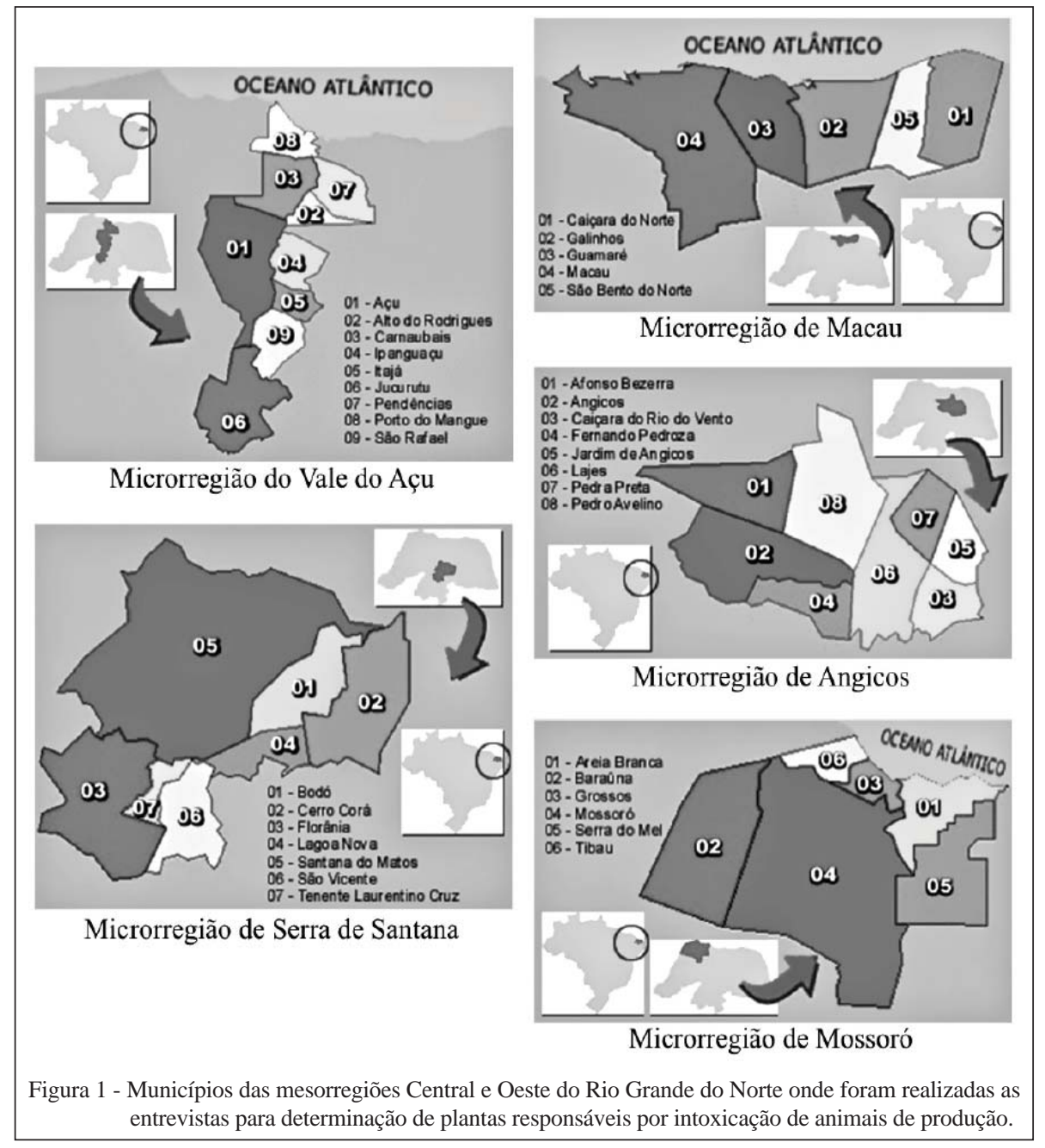

Ciência Rural, v.43, n.7, jul, 2013. 
Tabela 1 - Plantas relatadas como responsáveis por surtos de intoxicação de animais de produção nas mesorregiões Central e Oeste do Rio Grande do Norte.

\begin{tabular}{|c|c|c|c|c|}
\hline Nome científico & Família & Nome popular & Conheciam & Surtos \\
\hline Amorimia septentrionalis W.R. Anderson & Malphiaceae & tingui & 56 & 69 \\
\hline Anacardium occidentale L. & Anacardiaceae & cajueiro & 217 & 7 \\
\hline $\begin{array}{l}\text { Anadenanthera colubrina var. cebil (Griseb.) Altschul } \\
\text { (Piptadenia macrocarpa) }\end{array}$ & Fabaceae & angico & 162 & 11 \\
\hline Aspidosperma pyrifolium Mart. & Apocynaceae & pereiro & 180 & 251 \\
\hline Cnidoscolus quercifolius Pohl (C. phyllacantus) & Euphorbiaceae & favela & 94 & 3 \\
\hline Crotalaria retusa L. & Fabaceae & chocalho-de-cascavel & 161 & 38 \\
\hline Froelichia humboldtiana (Roem. \& Schult.) Seub. & Amaranthaceae & ervanço & 68 & 49 \\
\hline Indigofera suffruticosa Mill. & Fabaceae & anil & 193 & 141 \\
\hline Ipomoea asarifolia (Desr.) Roem. \& Schult. & Convolvulaceae & salsa & 192 & 282 \\
\hline Ipomoea carnea Jacq. & Convolvulaceae & algodão-bravo & 37 & 10 \\
\hline Leucaena leucocephala (Lam.) de Wit & Fabaceae & leucena & 53 & 4 \\
\hline Manihot carthaginensis subsp. glaziovii (Jacq.) Müll. Arg & Euphorbiaceae & maniçoba & 177 & 116 \\
\hline Manihot esculenta Crantz & Euphorbiaceae & mandioca & 217 & 16 \\
\hline Mimosa tenuiflora (Willd.) Poir. & Fabaceae & jurema-preta & 182 & 25 \\
\hline Nerium oleander L. & Apocynaceae & espirradeira & 35 & 4 \\
\hline Prosopis juliflora (Sw.) DC. & Fabaceae & algaroba & 183 & 25 \\
\hline Ricinus comunis L. & Euphorbiaceae & mamona & 165 & 38 \\
\hline Sorghum bicolor (L.) Moench & Poaceae & sorgo & 92 & 29 \\
\hline Sorghum halepense (L.) Pers. & Poaceae & capim-de-boi & 51 & 15 \\
\hline Tephrosia cinerea (L.) Pers. & Fabaceae & anil-falso & 88 & 76 \\
\hline Urochloa (Brachiaria) decumbens (Stapf) R.D. Webster & Poaceae & braquiária & 67 & 3 \\
\hline
\end{tabular}

Diversos surtos atribuídos a Indigofera suffruticosa não apresentaram a sintomatologia descrita para essa intoxicação. Dos 54 bovinos intoxicados, 32 (59,3\%) animais apresentaram graus variados de dermatites, muitas vezes, complicados com casos de miíases, sendo que houve relato de que dois desses animais morreram (mortalidade de 3,70\% e letalidade $6,25 \%$ ) e que outros 30 se recuperaram após a retirada da área com a planta. Foi relatado também que dois apresentaram graus variados de dermatite, mas se recuperaram após a retirada da área com a planta. Um ovino apresentou irritação ocular, evoluindo para cegueira e morte, e os outros 72 apresentaram graus variados de dermatites, com queda de pelo e irritação, principalmente da face e das orelhas, alguns casos complicados com miíases, morrendo oito animais. Todos os 16 equinos relatados apresentaram dermatites de graus variados, sem relato de complicação com miíase ou morte.

A intoxicação pelas folhas de Ricinus comunis era conhecida por 165 dos entrevistados, mas todos declararam desconhecer a toxicidade das sementes. Os produtores relatam que as intoxicações pelas folhas dessa planta ocorreram pela ingestão da planta cortada e murcha.

Seis equinos que ingeriam Leucaena leucocephala apresentaram alopecia da crina e cauda e, em todos os casos, houve recuperação ao serem retirados da pastagem com leucena.

\section{DISCUSSÃO}

Aspidosperma pyrifolium é conhecida como responsável por abortamentos em caprinos (SOUZA LIMA \& SOTO-BLANCO, 2010). Neste trabalho, foram relatados abortamentos principalmente em caprinos, mas também em ovinos e bovinos. Alguns produtores atribuíram a essa planta a ocorrência de malformações, caracterizadas por flexura dos membros pélvicos, prognatia, braquignatia, microftalmia, dermoide ocular e atresia anal. No entanto, esses efeitos teratogênicos, que, bastante específicos, são reconhecidamente produzidos por outra planta, Mimosa tenuiflora (PIMENTEL et al., 2007). M. tenuiflora é uma planta reconhecida como responsável por malformações em ruminantes, incluindo flexura dos membros pélvicos, prognatia, braquignatia, microftalmia, dermoide ocular e atresia anal (PIMENTEL et al., 2007). SILVA et al. (2006) verificaram que os produtores estavam reticentes em aceitar que essa planta fosse responsável por promover malformações. Neste estudo, 25 surtos de intoxicação foram atribuídos à M. tenuiflora, o que mostra que há uma mudança de postura dos produtores. 
Tabela 2 - Surtos de intoxicação por plantas, relatados nas mesorregiões Central e Oeste do Rio Grande do Norte.

\begin{tabular}{|c|c|c|c|c|c|c|}
\hline Planta & Espécie afetada & Surtos & Animais afetados & Morbidade (\%) & Letalidade (\%) & Mortalidade (\%) \\
\hline Amorimia septentrionalis & $\begin{array}{l}\text { bovina } \\
\text { caprina }\end{array}$ & $\begin{array}{l}68 \\
1\end{array}$ & $\begin{array}{l}122 \\
2\end{array}$ & $\begin{array}{l}8,13 \\
10\end{array}$ & $\begin{array}{l}97,5 \\
100\end{array}$ & $\begin{array}{l}7,93 \\
10\end{array}$ \\
\hline Anacardium occidentale & $\begin{array}{l}\text { bovina } \\
\text { caprina }\end{array}$ & $\begin{array}{l}5 \\
2\end{array}$ & $\begin{array}{l}15 \\
10\end{array}$ & $\begin{array}{l}8,11 \\
10\end{array}$ & $\begin{array}{l}0 \\
0\end{array}$ & $\begin{array}{l}0 \\
0\end{array}$ \\
\hline Anadenanthera colubrine & $\begin{array}{l}\text { bovina } \\
\text { caprina }\end{array}$ & $\begin{array}{l}10 \\
1\end{array}$ & $\begin{array}{l}21 \\
4\end{array}$ & $\begin{array}{l}3,56 \\
3,08\end{array}$ & $\begin{array}{l}76,2 \\
100\end{array}$ & $\begin{array}{l}2,72 \\
3,08\end{array}$ \\
\hline Aspidosperma pyrifolium & $\begin{array}{l}\text { bovina } \\
\text { caprina } \\
\text { ovina } \\
\text { cap/ov }\end{array}$ & $\begin{array}{l}36 \\
119 \\
43 \\
53\end{array}$ & $\begin{array}{l}69 \\
260 \\
106 \\
55\end{array}$ & $\begin{array}{l}2,58 \\
9,0 \\
5,14 \\
6,16\end{array}$ & $\begin{array}{l}0 \\
0 \\
0 \\
0\end{array}$ & $\begin{array}{l}0 \\
0 \\
0 \\
0\end{array}$ \\
\hline Cnidoscolus quercifolius & $\begin{array}{l}\text { caprina } \\
\text { cap/ov }\end{array}$ & $\begin{array}{l}2 \\
1\end{array}$ & $\begin{array}{l}19 \\
25\end{array}$ & $\begin{array}{l}6,33 \\
50,0\end{array}$ & $\begin{array}{l}73,7 \\
80,0\end{array}$ & $\begin{array}{l}4,67 \\
40,0\end{array}$ \\
\hline Crotalaria retusa & $\begin{array}{l}\text { bovina } \\
\text { caprina } \\
\text { ovina }\end{array}$ & $\begin{array}{l}9 \\
7 \\
20\end{array}$ & $\begin{array}{l}10 \\
13 \\
71\end{array}$ & $\begin{array}{l}2,32 \\
7,65 \\
18,2\end{array}$ & $\begin{array}{l}0 \\
61,5 \\
50,7\end{array}$ & $\begin{array}{l}0 \\
4,70 \\
10,0\end{array}$ \\
\hline Froelichia humboldtiana & $\begin{array}{l}\text { bovina } \\
\text { caprina } \\
\text { ovina } \\
\text { equina }\end{array}$ & $\begin{array}{l}10 \\
1 \\
4 \\
7\end{array}$ & $\begin{array}{l}53 \\
1 \\
48 \\
9\end{array}$ & $\begin{array}{l}6,65 \\
100 \\
13,6 \\
34,6\end{array}$ & $\begin{array}{l}11,3 \\
100 \\
35,4 \\
0\end{array}$ & $\begin{array}{l}0,75 \\
100 \\
4,81 \\
0\end{array}$ \\
\hline Indigofera suffruticosa & $\begin{array}{l}\text { bovina } \\
\text { caprina } \\
\text { ovina } \\
\text { equina } \\
\text { asinina }\end{array}$ & $\begin{array}{l}52 \\
10 \\
35 \\
37 \\
2\end{array}$ & $\begin{array}{l}54 \\
37 \\
73 \\
16 \\
2\end{array}$ & $\begin{array}{l}5,77 \\
23,1 \\
4,81 \\
39,0 \\
100\end{array}$ & $\begin{array}{l}14,8 \\
27,0 \\
12,3 \\
0 \\
0\end{array}$ & $\begin{array}{l}0,85 \\
6,25 \\
0,59 \\
0 \\
0\end{array}$ \\
\hline Ipomoea asarifolia & $\begin{array}{l}\text { bovina } \\
\text { caprina } \\
\text { ovina } \\
\text { cap/ov } \\
\text { equina }\end{array}$ & $\begin{array}{l}61 \\
34 \\
152 \\
34 \\
1\end{array}$ & $\begin{array}{l}411 \\
252 \\
388 \\
100 \\
1\end{array}$ & $\begin{array}{l}10,1 \\
12,6 \\
16,1 \\
10,9 \\
50\end{array}$ & $\begin{array}{l}71,5 \\
39,3 \\
61,8 \\
59,0 \\
100\end{array}$ & $\begin{array}{l}7,25 \\
4,95 \\
9,95 \\
6,41 \\
50\end{array}$ \\
\hline Ipomoea carnea & $\begin{array}{l}\text { bovina } \\
\text { caprina }\end{array}$ & $\begin{array}{l}3 \\
7\end{array}$ & $\begin{array}{l}3 \\
35\end{array}$ & $\begin{array}{l}25,0 \\
58,3\end{array}$ & $\begin{array}{l}33,3 \\
85,8\end{array}$ & $\begin{array}{l}8,33 \\
50,0\end{array}$ \\
\hline Leucaena leucocephala & equina & 4 & 6 & 100 & 0 & 0 \\
\hline Manihot carthaginensis & $\begin{array}{l}\text { bovina } \\
\text { caprina } \\
\text { ovina }\end{array}$ & $\begin{array}{l}109 \\
5 \\
2\end{array}$ & $\begin{array}{l}110 \\
7 \\
4\end{array}$ & $\begin{array}{l}3,78 \\
7,78 \\
6,67\end{array}$ & $\begin{array}{l}88,2 \\
57,1 \\
100\end{array}$ & $\begin{array}{l}3,35 \\
4,44 \\
6,67\end{array}$ \\
\hline Manihot esculenta & $\begin{array}{l}\text { bovina } \\
\text { ovina } \\
\text { equina }\end{array}$ & $\begin{array}{l}14 \\
1 \\
1\end{array}$ & $\begin{array}{l}89 \\
6 \\
1\end{array}$ & $\begin{array}{l}21,4 \\
20,0 \\
100\end{array}$ & $\begin{array}{l}23,6 \\
100 \\
0\end{array}$ & $\begin{array}{l}5,05 \\
20,0 \\
0\end{array}$ \\
\hline Mimosa tenuiflora & $\begin{array}{l}\text { caprina } \\
\text { ovina } \\
\text { cap/ov }\end{array}$ & $\begin{array}{l}11 \\
7 \\
7\end{array}$ & $\begin{array}{l}49 \\
113 \\
20\end{array}$ & $\begin{array}{l}7,18 \\
10,4 \\
10,0\end{array}$ & $\begin{array}{l}81,6 \\
73,4 \\
25,0\end{array}$ & $\begin{array}{l}5,86 \\
6,58 \\
2,50\end{array}$ \\
\hline Nerium oleander & $\begin{array}{l}\text { bovina } \\
\text { asinina }\end{array}$ & $\begin{array}{l}3 \\
1\end{array}$ & $\begin{array}{l}36 \\
1\end{array}$ & $\begin{array}{l}32,7 \\
100\end{array}$ & $\begin{array}{l}61,1 \\
100\end{array}$ & $\begin{array}{l}20,0 \\
100\end{array}$ \\
\hline Prosopis juliflora & $\begin{array}{l}\text { bovina } \\
\text { caprina }\end{array}$ & $\begin{array}{l}15 \\
10\end{array}$ & $\begin{array}{l}34 \\
73\end{array}$ & $\begin{array}{l}2,34 \\
10,4\end{array}$ & $\begin{array}{l}64,7 \\
54,2\end{array}$ & $\begin{array}{l}1,52 \\
4,71\end{array}$ \\
\hline Ricinus communis & $\begin{array}{l}\text { bovina } \\
\text { caprina } \\
\text { equina } \\
\text { suína }\end{array}$ & $\begin{array}{l}31 \\
3 \\
1 \\
1\end{array}$ & $\begin{array}{l}69 \\
7 \\
1 \\
1\end{array}$ & $\begin{array}{l}9,37 \\
8,23 \\
100 \\
\text { ND }\end{array}$ & $\begin{array}{l}56,5 \\
100 \\
100 \\
100\end{array}$ & $\begin{array}{l}5,30 \\
8,23 \\
100 \\
\text { ND }\end{array}$ \\
\hline Sorghum bicolor & $\begin{array}{l}\text { bovina } \\
\text { equina }\end{array}$ & $\begin{array}{l}28 \\
1\end{array}$ & $\begin{array}{l}69 \\
1\end{array}$ & $\begin{array}{l}4,99 \\
50\end{array}$ & $\begin{array}{l}69,6 \\
100\end{array}$ & $\begin{array}{l}3,47 \\
50\end{array}$ \\
\hline Sorghum halepense & bovina & 15 & 18 & 15,0 & 66,7 & 10,0 \\
\hline Tephrosia cinerea & $\begin{array}{l}\text { caprina } \\
\text { ovina }\end{array}$ & $\begin{array}{l}75 \\
1\end{array}$ & $\begin{array}{l}184 \\
7\end{array}$ & $\begin{array}{l}17 \\
7\end{array}$ & $\begin{array}{l}88,0 \\
85,7\end{array}$ & $\begin{array}{l}14,9 \\
6,0\end{array}$ \\
\hline Urochloa decumbens & $\begin{array}{l}\text { bovina } \\
\text { ovina }\end{array}$ & $\begin{array}{l}2 \\
1\end{array}$ & $\begin{array}{l}5 \\
3\end{array}$ & $\begin{array}{l}6,02 \\
30,0\end{array}$ & $\begin{array}{l}100 \\
100\end{array}$ & $\begin{array}{l}6,02 \\
30,0\end{array}$ \\
\hline
\end{tabular}

cap/ov: sem determinação se eram caprinos ou ovinos.

ND: não determinado.

Ciência Rural, v.43, n.7, jul, 2013. 
Indigofera suffruticosa é uma planta conhecida por causar anemia hemolítica com hemoglobinúria em bovinos (SALVADOR et al., 2010), ovinos e caprinos (FIGUEIREDO et al., 2012). Além dessas espécies, os entrevistados neste trabalho também relataram a ocorrência da intoxicação em equinos e asininos. Em seis vacas severamente afetadas, foi relatada a ocorrência de abortamentos. Esse efeito provavelmente é resultante da severa toxicidade materna, afetando a transferência placentária de nutrientes para o feto (GIAVINI \& MENEGOLA, 2012). Outros efeitos relatados nas entrevistas foram dermatites e irritação ocular. Como esses efeitos ainda não foram comprovados experimentalmente, não se pode afirmar se foram realmente produzidos pela ingestão de $\mathbf{I}$. suffruticosa.

As plantas cianogênicas relatadas como causa de intoxicação pelos entrevistados neste trabalho foram Manihot carthaginensis subsp. glaziovii (M. glaziovii), Manihot esculenta, Anadenanthera colubrina var. cebil (Piptadenia macrocarpa), Sorghum bicolor, Sorghum halepense e Cnidoscolus quercifolius (C. phyllacantus). Em muitos casos, os relatos eram de ingestão de restos das plantas cortadas ou quebradas. Nas plantas cianogênicas, o cianeto está presente na forma de glicosídeos; quando as plantas secam ou murcham, os glicosídeos cianogênicos entram em contato com enzimas que os degradam, liberando o cianeto (HARAGUCHI \& GÓRNIAK, 2008). Assim, as partes das plantas recentemente cortadas ou quebradas apresentam cianeto livre; além disso, parecem ser mais palatáveis, o que favorece a intoxicação.

Amorimia septentrionalis, anteriormente identificada como Mascagnia rigida, é uma planta que promove morte súbita (PACÍFICO DA SILVA et al., 2008; RIET-CORREA et al., 2009). A movimentação dos animais é considerada pelos produtores um fator que exacerba a apresentação dos sinais clínicos da intoxicação, o que já foi descrito anteriomente (PACÍFICO DA SILVA et al., 2008; RIET-CORREA et al., 2009). Isso ocorre porque o princípio tóxico é o monofluoracetato, que interfere no metabolismo energético nas mitocôndrias ao bloquear o ciclo de Krebs (CUNHA et al., 2012; LEE et al., 2012).

Outra intoxicação frequentemente relatada foi por Tephrosia cinerea. A ingestão dessa planta é responsável por hepatotoxicidade crônica progressiva, caracterizada clinicamente por ascite e perda de peso. A intoxicação foi confirmada experimentalmente em ovinos (SANTOS et al., 2007), que foi a espécie mais acometida neste estudo. Também foram relatados surtos em caprinos; a intoxicação nessa espécie é bastante provável por apresentar mesmo quadro que os ovinos, mas precisa ser comprovada experimentalmente.

A principal planta responsável por fotossensibilização na região estudada é Froelichia humboldtiana, mas também foram relatados surtos promovidos por Urochloa (Brachiaria) decumbens. A ocorrência de fotossensibilização por F. humboldtiana já foi relatada anteriormente na mesma região estudada (MACEDO et al., 2006).

Neste trabalho, a intoxicação por Crotalaria retusa foi relatada em bovinos, ovinos e caprinos. Surtos naturais já foram descritos nessas espécies (LUCENA et al., 2010), o que confirma a importância dessa intoxicação. Por outro lado, foram relatados casos em equinos na região do Seridó do Rio Grande do Norte (SILVA et al., 2006) e no Sertão da Paraíba (ASSIS et al., 2009). Apesar de não ter sido relatada, é possível que a intoxicação natural por $\boldsymbol{C}$. retusa também ocorra em equídeos na região aqui estudada.

Ipomoea asarifolia é uma planta responsável por doença tremorgênica, descrita em caprinos, ovinos, bovinos e bubalinos de diversos estados das regiões Norte e Nordeste do Brasil (BARBOSA et al., 2005; ASSIS et al., 2009; MELLO et al., 2010; COSTA et al., 2011a, 2011b). Os criadores de ruminantes em áreas com a planta demonstraram conhecer a intoxicação, o que resulta em baixa mortalidade por removerem, sempre que possível, os animais para áreas sem a planta, quando apresentam as primeiras manifestações clínicas.

Os entrevistados relataram que Ipomoea carnea foi responsável por intoxicações em caprinos e bovinos, principalmente na primeira espécie, o que está de acordo com a literatura (RIET-CORREA et al., 2009; TOKARNIA et al., 2012). Um fato bastante relatado foi que a ingestão da planta, que ocorre apenas na falta de outro alimento, resulta em vício nos animais, que passariam a preferir esta planta em detrimento de outras.

A intoxicação por Leucaena leucocephala foi relatada em seis equinos, que apresentaram alopecia da crina e cauda, mas se recuperaram quando cessou a ingestão da planta. No Brasil, a alopecia promovida espontaneamente por essa planta já foi descrita em um ovino na Paraíba (RIET-CORREA et al., 2004) e em um caprino no Rio de Janeiro (PEIXOTO et al., 2008), e foi citado em equinos (RIET-CORREA et al., 2009).

A intoxicação por Anacardium occidentale foi relatada em bovinos e caprinos. Essa intoxicação foi descrita anteriormente em bovinos, e ocorre pela ingestão do pseudo-fruto (caju), provavelmente causada pela formação de etanol por 
meio de fermentação bacteriana (RIBEIRO FILHO \& SOTO-BLANCO, 2012).

Uma planta relatada como responsável por mortalidade praticamente sem manifestações clínicas foi Nerium oleander. As intoxicações ocorreram por ingestão de partes cortadas da planta, como já descrito anteriormente (SOTO-BLANCO et al., 2006). Foram relatados surtos de intoxicação por Prosopis juliflora em bovinos e caprinos, constatando-se ser bem conhecida pelos produtores e já relatada (CÂMARA et al., 2009; RIET-CORREA et al., 2009; TOKARNIA et al., 2012).

Neste trabalho, foram relatados surtos de intoxicação pelas folhas de Ricinus communis em bovinos, ovinos, caprinos e suíno. Não há descrição natural desse tipo de intoxicação no Brasil, mas já foi confirmada experimentalmente (TOKARNIA et al., 1975). É importante ressaltar que os entrevistados declararam desconhecer a toxicidade das sementes de $\boldsymbol{R}$. communis. Essas sementes possuem elevada toxicidade e mesmo o resíduo obtido após a extração do óleo pode permanecer tóxico (SOTO-BLANCO et al., 2002).

As intoxicações por plantas são bastante frequentes nos animais de produção das mesorregiões Central e Oeste do Rio Grande do Norte. A utilização de ferramentas de análise epidemiológica é de grande utilidade nesse tipo de trabalho. No entanto, são necessárias ações de extensão para melhor divulgação das informações sobre as espécies tóxicas, bem como das medidas disponíveis para evitar as intoxicações.

\section{AGRADECIMENTOS}

Trabalho financiado pelo INCT para o controle das intoxicações por plantas, Conselho Nacional de Desenvolvimento Científico e Tecnológico (CNPq) (Proc. nº573534/2008-0).

\section{COMITÊ DE ÉTICA E BIOSSEGURANÇA}

Declaramos, para os devidos fins, que assumimos toda e qualquer responsabilidade sobre os procedimentos que foram realizados no trabalho intitulado Plantas Tóxicas das Regiões Central e Oeste do Rio Grande do Norte. Da mesma forma, colocamo-nos à disposição para quaisquer esclarecimentos que se façam necessários.

\section{REFERÊNCIAS}

ASSIS, T.S. et al. Intoxicações por plantas em ruminantes e equídeos no Sertão Paraibano. Pesquisa Veterinária Brasileira, v.29, p.919-924, 2009. Disponível em: <http://dx.doi.org/10.1590/ S0100-736X2009001100010>. Acesso em: 5 set. 2012. doi: 10.1590/S0100-736X2009001100010.

BARBOSA, J.D. et al. Intoxicações experimental e natural por Ipomoea asarifolia (Convolvulaceae) em búfalos e outros ruminantes. Pesquisa Veterinária Brasileira, v.25, p.231234, 2005. Disponível em: <http://dx.doi.org/10.1590/S0100736X2005000400008>. Acesso em: 5 set. 2012. doi: 10.1590/ S0100-736X2005000400008.

CÂMARA, A.C.L. et al. Intoxicação espontânea por vagens de Prosopis juliflora (Leg. Mimosoideae) em bovinos em Pernambuco. Pesquisa Veterinária Brasileira, v.29, p.233240, 2009. Disponível em: <http://dx.doi.org/10.1590/S0100736X2009000300008>. Acesso em: 5 set. 2012. doi: 10.1590/ S0100-736X2009000300008.

COSTA, A.M.D. et al. Plantas tóxicas de interesse pecuário na região do Ecótono Amazônia e cerrado. Parte I: Bico do Papagaio, Norte do Tocantins. Acta Veterinaria Brasilica, v.5, p.178-183, 2011a. Disponível em: <http://periodicos.ufersa.edu.br/revistas/ index.php/acta/article/view/2091>. Acesso em: 5 set. 2012.

COSTA, A.M.D. et al. Plantas tóxicas de interesse pecuário na região do Ecótono Amazônia e cerrado. Parte II: Araguaína, Norte do Tocantins. Acta Veterinaria Brasilica, v.5, p.317-324, 2011b. Disponível em: <http://periodicos.ufersa.edu.br/revistas/index. php/acta/article/view/2349>. Acesso em: 5 set. 2012.

CUNHA, L.C. et al. Isolation and characterization of sodium 2-fluoroacetate from Mascagnia rigida using chromatography and infrared spectroscopy. Toxicon, v.60, p.329-332, 2012. Disponível em: <http://dx.doi.org/10.1016/j.toxicon.2012.04.346>. Acesso em: 5 set. 2012. doi: 10.1016/j.toxicon.2012.04.346.

FIGUEIREDO, A.P.M. et al. Intoxicação experimental por Indigofera suffruticosa em caprinos e ovinos. Pesquisa Veterinária Brasileira, v.32, p.126-130, 2012. Disponível em: <http://dx.doi.org/10.1590/S0100-736X2012000200006>. Acesso em: 5 set. 2012. doi: 10.1590/S0100-736X2012000200006.

GIAVINI, E.; MENEGOLA, E. The problem of maternal toxicity in developmental toxicity studies. Regulatory Toxicology and Pharmacology, v.62, p.568-570, 2012. Disponível em: <http:// dx.doi.org/10.1016/j.yrtph.2011.11.021>. Acesso em: 5 set. 2012. doi: 10.1016/j.yrtph.2011.11.021.

HARAGUCHI, M.; GÓRNIAK, S.L. Introdução ao estudo das plantas tóxicas. In: SPINOSA, H.S. et al. Toxicologia aplicada à medicina veterinária. São Paulo, Manole, 2008. p.367-414.

LEE, S.T. et al. Detection of monofluoroacetate in Palicourea and Amorimia species. Toxicon, v.60, p.791-796, 2012. Disponível em: <http://dx.doi.org/10.1016/j.toxicon.2012.05.029>. Acesso em: 5 set. 2012. doi: 10.1016/j.toxicon.2012.05.029.

LUCENA, R.B. et al. Intoxicação por alcaloides pirrolizidínicos em ruminantes e equinos no Brasil. Pesquisa Veterinária Brasileira, v.30, p.447-452, 2010. Disponível em: <http://dx.doi. org/10.1590/S0100-736X2010000500013>. Acesso em: 5 set. 2012. doi: $10.1590 / S 0100-736 X 2010000500013$.

MACEDO, M.F. et al. Fotossensibilização em animais de produção na região semi-árida do Rio Grande do Norte. Arquivos do Instuto Biológico, v.73, p.251-254, 2006. Disponível em: $<$ http://www.biologico.sp.gov.br/docs/arq/V73_2/macedo.PDF>. Acesso em: 5 set. 2012.

MELLO, G.W.S. et al. Plantas tóxicas para ruminantes e equídeos no Norte Piauiense. Pesquisa Veterinária Brasileira, v.30, p.1-9, 2010. Disponível em: <http://dx.doi.org/10.1590/S0100- 
736X2010000100001>. Acesso em: 5 set. 2012. doi: 10.1590/ S0100-736X2010000100001.

PACÍFICO DA SILVA, I. et al. Intoxicação natural pelas folhas de Mascagnia rigida (Malpighiaceae) em ovinos. Arquivos do Instuto Biológico, v.75, p.229-233, 2008. Disponível em: <http:// www.biologico.sp.gov.br/docs/arq/v75_2/silva.pdf $>$. Acesso em: 5 set. 2012.

PEIXOTO, P.V. et al. Spontaneous poisoning by Leucaena leucocephala in a goat from Rio de Janeiro state, Brazil. Ciência Rural, v.38, p.551-555, 2008. Disponível em: <http://dx.doi. org/10.1590/S0103-84782008000200044>. Acesso em: 5 set. 2012. doi: 10.1590/S0103-84782008000200044.

PIMENTEL, L.A. et al. Mimosa tenuiflora as a cause of malformations in ruminants in the Northeastern Brazilian semiarid rangelands. Veterinary Pathology, v.44, p.928-931, 2007. Disponível em: <http://dx.doi.org/10.1354/vp.44-6-928>. Acesso em: 5 set. 2012. doi: 10.1354/vp.44-6-928.

RIBEIRO FILHO, M.R.; SOTO-BLANCO, B. Poisoning by cashew apple (Anacardium occidentale L) in cattle. Acta Scientiae Veterinariae, v.40, art.1083, 2012. Disponível em: $<$ http://www.ufrgs.br/actavet/40-4/PUB\%201083.pdf>. Acesso em: 5 set. 2012.

RIET-CORREA, F. et al. Intoxicação por Leucaena leucocephala em ovinos na Paraíba. Pesquisa Veterinária Brasileira, v.24, supl., p.52, 2004

RIET-CORREA, F. et al. Poisonings by plants, mycotoxins and related substances in brazilian livestock. Patos: Sociedade Vicente Pallotti, 2009. 246p.

SALVADOR, I.S. et al. Intoxicação por Indigofera suffruticosa (Leg. Papilionoideae) em bovinos. Pesquisa Veterinária Brasileira, v.30, p.953-957, 2010. Disponível em: <http://dx.doi. org/10.1590/S0100-736X2010001100009>. Acesso em: 5 set. 2012. doi: 10.1590/S0100-736X2010001100009.
SANTOS, J.C.A. et al. Toxic hepatopathy in sheep associated with the ingestion of the legume Tephrosia cinerea. Journal of Veterinary Diagnostic Investion, v.19, p.690-694, 2007. Disponível em: <http://dx.doi.org/10.1177/104063870701900612>. Acesso em: 5 set. 2012. doi: 10.1177/104063870701900612.

SCHONS, S.V. et al. Intoxicações por plantas em ruminantes e equídeos na região central de Rondônia. Ciência Rural, v.42, p.1257-1263, 2012. Disponível em: <http://dx.doi.org/10.1590/ S0103-84782012005000047>. Acesso em: 5 set. 2012. doi: 10.1590/S0103-84782012005000047.

SILVA, D.M. et al. Plantas tóxicas para ruminantes no Seridó Ocidental e Oriental do Rio Grande do Norte. Pesquisa Veterinária Brasileira, v.26, p.223-236, 2006. Disponível em: <http://dx.doi.org/10.1590/S0100-736X2006000400007>. Acesso em: 5 set. 2012. doi: 10.1590/S0100-736X2006000400007.

SOTO-BLANCO, B. et al. Ricinus communis cake poisoning in a dog. Veterinary and Human Toxicology, v.44, p.155-156, 2002.

SOTO-BLANCO, B. et al. Acute cattle intoxication from Nerium oleander pods. Tropical Animal Health and Production, v.38, p.451-454, 2006. Disponível em: <http://dx.doi.org/10.1007/ s11250-006-4400-x>. Acesso em: 5 set. 2012. doi: 10.1007/ s11250-006-4400-x.

SOUZA LIMA, M.C.J.; SOTO-BLANCO, B. Poisoning in goats by Aspidosperma pyrifolium Mart.: Biological and cytotoxic effects. Toxicon, v.55, p.320-324, 2010. Disponível em: <http:// dx.doi.org/10.1016/j.toxicon.2009.08.004>. Acesso em: 5 set. 2012. doi: 10.1016/j.toxicon.2009.08.004.

TOKARNIA, C.H. et al. Intoxicação experimental em bovinos pelas folhas de Ricinus communis. Pesquisa Agropecuária Brasileira Série Veterinária, v.10, p.1-7, 1975.

TOKARNIA, C.H. et al. Plantas tóxicas do brasil para animais de produção. 2.ed. Rio de Janeiro, Helianthus, 2012. 586p. 